\title{
Encourage non-designer's design: continuous value creation in manufacturing products and services
}

\author{
T. Hara ${ }^{a}{ }^{*}$, T. Arai $(1)^{b}$ \\ a Research into Artifacts, Center for Engineering, The University of Tokyo, Chiba 277-8568, Japan \\ ${ }^{b}$ Department of Precision Engineering, The University of Tokyo, Tokyo 133-8756, Japan
}

The advancement of ICT has enabled customer participatory design such as mass-customization. Increase of a customer's contact to design processes gives rise to (a) the subsequent clarification of requirements through product configuration by the customers themselves; (b) the real-time configuration based on the estimations of customer tastes by manufacturers; and (c) the organizational data acquisition of manufacturers of customers' tastes for improvement of the design activities of manufacturers. This paper argues for continuous value creation by means of combining 'designing by designers' and 'designing by non-designers' for products. Tourism is studied as a typical example of design by non-designer. Indispensable requirements are obtained to encourage non-designer's design.

Keywords: Design, Customization, Personalization

\section{Introduction}

With the advancement of information technology and web technology, the role of the customer in manufacturing products and services has clearly changed. Referred to as a prosumer, a customer can be not only a payer and consumer, but also play roles of a quality controller, co-producer, and/or co-marketer [1]. In the servicification process for manufacturers, all their design activities are covered, from simple 'engineering design' to 'service design' in terms of customer orientation [2]. This implies that manufacturers need to step deeply in the entire customer experience gained with products and services, by incorporating active customer involvement. However, in the field of engineering design, 'design by professional engineers' is predominant. New enabling environments must be created to allow non-designers to design the aspects of products [3] in order to enable manufacturers to cope with divergent tastes by customers. A CAD system for product service systems (PSSs) previously developed by the authors for 10 years [4] [5] [6], is also being implemented under assumption of its use among professional designers.

Mass customization, which is the mass production of highly customized products, is a popular and good example of utilizing customer participation in the design phase. Motivated by such participatory design, this paper argues how to encourage design by non-designers toward continuous value creation in manufacturing products. Many hints are obtained in the study of packaged tours in tourism, where non-designers tend to plan the tour and to participate the value creation at the use of the tour.

The rest of this paper is organized as follows. Section 2 reviews earlier studies relevant to customer participatory design. Section 3 illustrates the relationships between a provider and two types of customers, while focusing on design activities. In Section 4, tourism is studied in order to exemplify the encouragement of design by non-designers. The tourism service was considered because it is a typical service in which a user's activities (i.e., customer experience) are greatly emphasized, while its design processes are similar to those of physical products. Section 5 provides a discussion and Section 6 concludes the paper.

\section{Related studies}

\subsection{Value co-creation and participant learning}

Value co-creation in the emergent field of service research is a broader concept than co-design or participatory design [7] [8]. A study by Payne et al. [7] confirmed the need for a process-based value creation framework with the following three main components: a customer's value-creating processes, a supplier's value-creating processes, and encounter processes. At both ends of Payne's model, there is learning by the parties involved: the organization and the customer.

Most studies have primarily addressed examples of existing services, even though the concept of co-creation originally attracted attention for the design of new services [9]. Little is known about and scant research has been done on how customers engage in value co-creation from the viewpoint of engineering design.

\subsection{Mass customization and product variety}

Mass customization, which has become the solution of choice for many companies, originates from the mass production approach, and it has, from that point, moved toward customization. Silveira et al. suggested eight generic levels of mass customization [10] based on a literature review: design, fabrication, assembly, additional work, additional services, packaging and distribution, usage, and standardization. Among these, design and assembly level customizations are the most studied in terms of participatory design involving customers.

Modular design and assembly systems in customization bring high product variety. However, increased product variety might have significant negative impact on the performance in production. To assess the impact of product variety on performance, Hu et al. proposed a unified measure of complexity by integrating both product variety and assembly process information [11]. 
Gilmore and Pine [12] identified four types of mass customization approaches that companies can pursue: collaborative customization, adaptive customization, transparent customization, and cosmetic customization.

\subsection{Personalization}

Personalization, which is a popular term in web design, involves satisfying each customer as an individual. The difference between customization and personalization is that the former starts with design attributes that can meet the explicit requirements of defined market segments, whereas the latter is an active interaction process between the customer and manufacturer to elicit the customer's requirements and then define the specifications that satisfy them [13].

\subsection{Two design mindsets: expert mindset and participatory mindset}

In mass customization and personalization, one of the most important stages is design and/or production through customer participation. Sanders presented the current landscape of humancentered design, showing two distinct cultures of design research: the expert mindset and the participatory mindset [14]. The expert mindset involves designing for people using specialized skills and expertise, while probing for or provoking responses from people, who are often referred to as the audience. The participatory mindset involves designing while incorporating the people who will benefit from the design into the design process as partners. Participatory designers respect the expertise of partners and view them as co-creators in the process. This participatory mindset is an enabler to user-driven innovation of both products and services (e.g., [15] [16]).

\section{Value creation by encouraging design by non-designers}

This section presents a basic framework for combining the two types of design activities according to the studies mentioned above so that manufacturers can continuously improve their products. The upper portion of Figure 1 shows two classes of customers: an active customer who prefers to participate in the design processes for products and a common customer who simply purchases products designed by professional designers. The design methods may change accordingly: novel methods encourage the efforts of non-designers, in conjunction with the conventional methods that are widely studied in engineering history, as shown in the lower portion of the figure. The former are defined as methods under the participatory mindset, while the latter are methods under the expert mindset. Whosoever wants to design products does not build up their requirements

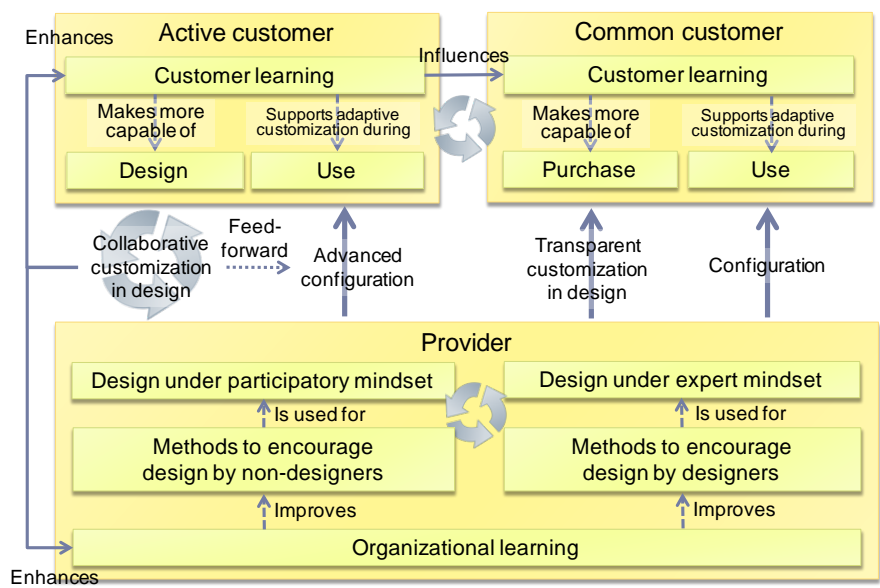

Figure 1 Basic framework for combining two design activities. explicitly and may not be able to compute complicated constraints among design parameters. Thus, the methods under the participatory mindset may include at least an extraction process for the requirements, constraint solvers, intelligent recommendation, and so on.

As shown in the left portion of the figure, collaborative customization in design between the active customer and manufacturer enhances both the customer learning and organizational learning explained in Section 2.1. At one side is organizational learning, which refers to the continuous manufacturer's learning more and more about the customer, along with the co-creation opportunities, planning and implementation, and the metrics involved in handling the encounter processes correctly. In the same manner, through interaction with the manufacturer, the active customer experiences customer learning, where the customer becomes more capable of understanding his/her own emotions, cognition, and behavior. In addition, the active customer becomes more capable of utilizing the tools provided by the manufacturer to design and create the most suitable type of product for the customer. Moreover, the advanced configuration of the product through the participatory design process is expected based on estimations of a customer's states by manufacturers.

Transparent customization in designs for common customers provides pre-defined products to each customer segment without informing the common customer that it has been customized to their needs. This requires the manufacturer to continuously collect information and make an assessment of the customer's needs in other ways to create suitable product offerings. A cocreation process with an active customer may provide the needed support to accumulate such information about customers. Regarding the use phase of a product by customers, both types may adapt products to meet their needs if the products are designed in a fashion that allows the customers to alter the product themselves. This process may also be supported by continuous customer learning, which is enhanced through the cocreation process.

\section{Design by non-designer in tourism}

This section exemplifies continuous value creation in the tourism industry by focusing on the packaged tours planned by a travel agency and individual tours planned by free independent travelers. The authors started a new research project on tourism called Rosetta (Research on Service Engineering for Tourists and Travel Agency) in October 2010 [17]. The goal of this project is to establish a methodology to engineer competitive services by encouraging customer participatory design. Tour services for inbound tourists are especially studied because these must deal with high heterogeneity, which has been referred to as a key characteristic of service.

\subsection{Heterogeneity and diversity of free independent travelers}

Japan is labeled as an underdeveloped country in the field of inbound tourism. To build a tourism-oriented nation, the Japanese government has set a target to increase the number of foreign tourists visiting Japan to an annual total of 25 million by 2019. Visitors from Western countries have always preferred traveling as free independent travelers (FITs). However, in the recent years, the number of FITs from Asian countries such as Korea, Taiwan, and China, has started to increase. For this reason, it is apparent that attracting individual travelers is becoming more important for achieving the target. FITs make their own travel plans and personally select their accommodations and sites to visit. In this process, it is very difficult for individual travelers that are not familiar with a tourist destination to visualize and 
efficiently plan visits to interesting tourist areas within a limited amount of vacation time.

In order to ensure the influx of greater numbers of such FITs from a wide variety of countries, the following methods need to be developed: (a) a method to understand the heterogeneity and diversity of inbound tourists, (b) a method to help FIT travelers to make travel plans that suit these various needs, and (c) a method to develop packaged tours that can immediately respond to their travel plans and needs.

\subsection{Design of packaged tours and related issues}

Through a series of interviews with JTB, the biggest travel agency in Japan, it was clarified that the design processes for packaged sightseeing tours are similar to those of manufactured products. These include the following: (a) planning of the tour concept, (b) function design with functional deployment and embodiment, (c) component production (e.g., arrangement of accommodations, transportation, and tickets for attractions), and (d) product assembly for connecting components. This indicates that the technological design methods used for physical products can be usefully applied to the design of packaged tours.

A total of 172 packaged tours from the travel agency were available for purchase by inbound tourists in 2010. However, a mere $10 \%$ of these packages, that is, the standard types, accounted for approximately $80 \%$ of all tour sales. This suggests that only a limited variety of tours effectively provide customer satisfaction. To break the status quo, the travel agency feels that its mindset needs to be shifted from mass production to individualization to meet the wide variety of needs of FITs.

\subsection{Proposed ecosystem for two design activities}

The research project aims at continuous value creation in the tourism industry by combining 'designing by designer' and 'designing by non-designer.' Figure 2 shows a schematic illustration of such value creation, capturing the needs of both packaged tour users and FITs. It focuses on the packaged tours planned by a travel agency (i.e., professional designer) and individual tours planned by FITs (i.e., non-designers). As shown in the left portion of the figure, up to now, the travel agency has focused on selling standard packaged tours to ordinary tourists. In this framework, a new tour planning service is provided to FITs to enable them to design their own itineraries. This travelerdriven tour planning service enabled by the interactive tour planning system not only helps to meet the needs of FITs but also continuously collects a large amount of data on inbound tourists and their itineraries. By constantly accumulating such data and learning about inbound tourists, a computerized system for designing the prearranged tour line-ups for experts is developed to allow a variety of more attractive packaged tours to be

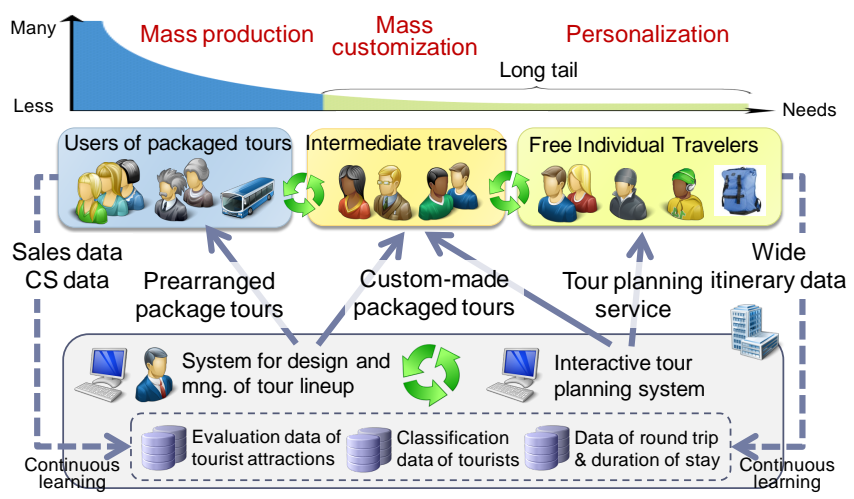

Figure 2 Continuous value creation in tourism service. prepared. Then, the mass customization and personalization enabled by utilizing the above two systems appeals to intermediate users who might buy packaged tours if the tours can be more or less individualized to meet their needs. In short, the expert approach and the participatory approach influence one another for continuous value creation. Finally, a basis is established for these new types of tourism products, which have both the cost advantage of concentrated procurement and individual customization.

\subsection{Two design systems for sightseeing tours}

Figure 3 maps the research topics that the authors are currently working on in the project. The horizontal dimension describes the expert mindset and participatory mindset according to Sander's work explained in Section 2.4, while the vertical dimension describes the design thinking and analytical thinking to clarify the purpose of each research topic. The arrows in the figure show the research directions of the project. As explained in the previous section, this project aims at developing a new methodology that integrates design methodologies for both designers and nondesigners, as shown in the middle of the figure. The rest of this section details the two design systems represented as black circles in the figure.

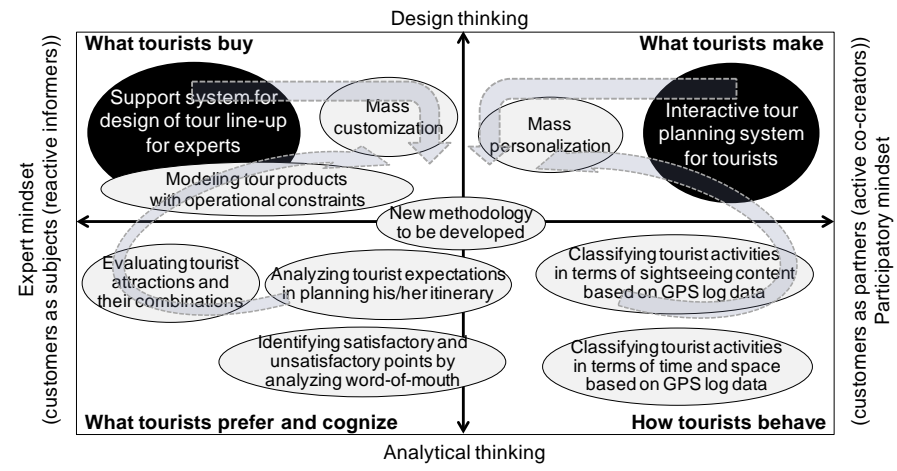

Figure 3 Research map in terms of expert mindset and participatory mindset.

\section{Interactive tour planning system: participatory mindset}

Kurata, who is involved in the project, has been working on developing the CT-Planner: a traveler-driven and interactive planning support system for one-day trips in specific areas [18]. The CT-Planner generates itinerary recommendations for a user, based on information provided by the user about the place of departure, destination, travel period, and five travel preferences. Based on these suggested itineraries, the user and system can then interact and work toward a gradual clarification, even for the needs that were extremely vague in the beginning. Finally, the user devises a suitable travel plan by customizing and improving the plan through repeated interaction with the system.

\section{Support system for design of tour line-up: expert mindset}

Figure 4 describes a growth model for packaged tours provided by the travel agency. Figure 4(a) shows the current structure of packaged tours explained in Section 4.2. The modularization techniques used in manufacturing products are applied to tourism products, in order to improve tour line-ups, ensuring that they can accommodate a wide variety of tourist needs shown in Figure 4(b). In variation design, when applied to mass customization, it is assumed that a small number of components will be used to construct a medium number of modules, which are then combined to create a large number of final products. Based on this product structure, the authors have already developed a variation design method for packaged tours, while ensuring the feasibility of mutual tours. 


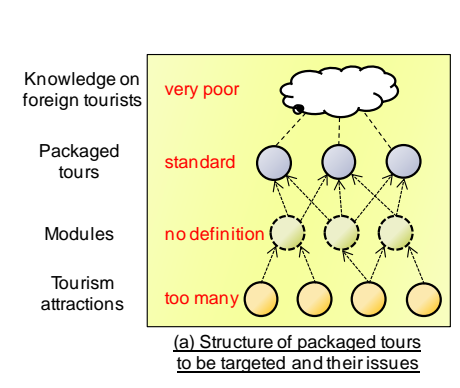

Classification of inbound tourist
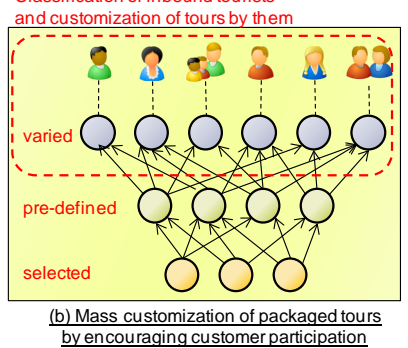

Figure 4 As-is and to-be structures of packaged tours.

\section{Discussion}

As explained in the previous section, The CT-Planner is a promising tool to support design by a non-designer. However, this system is still faced with the following problems at the time of writing this manuscript. The first involves the difficulty that users may not appropriately project the images of their preferred travel onto the system: It is significant in the early stages of trip planning; individual travelers may not have concrete ideas about making a trip to an unfamiliar place. The other problem involves the large load for users due to many interactions with the system.

This section discusses the nature of these problems in order to summarize common participatory design issues that will be studied in the future.

\subsection{Paradox of the active customer}

A concept called 'the paradox of the active user' [19] lies behind the above problems. Even though an active customer is indispensable in participatory design, it should be noted that many customers are not much interested in the details of the design system. Far from that they do not want to spend time setting up complex personalization features. Their aim is to simply explore and obtain results right away rather than peruse learning packages. This implies that customers focus on endproducts at the expense of prerequisite learning. For more experienced users, the paradox should be noted more. An approach to the paradox could be to develop design support methods and systems that enable customers to easily design based on prototypes of tangible end-products, requiring less motivation to learn.

\subsection{Prototype-based design for hot start}

To solve the paradox of the active customer, prototype-based design for hot start may be introduced. It provides a good boost to non-designers by helping them recognize their implicit requirements with less learning. A non-designer selects an initial configuration out of several different types of prototypes prepared in advance, where a prototype comprises a preference model and a design solution. Next, the user interacts with the system on the basis of the initial configuration, while improving both its preference model and design solution iteratively. Such design processes may satisfy the user because it helps to fill the gap between the current configuration and the user's image of the ideal end-product.

For the tourism project, to realize such prototype-based design for hot start on the CT-Planner, about 500 person-day data on the activities of inbound tourists were collected using the global positioning system (GPS) through field experiments in Tokyo. Pre-defined configurations for the preference model and itinerary will then be established by classifying the collected data. The results of this implementation will be presented in a future work.

\section{Conclusion}

Design by a professional and design by a non-professional cannot be mutually exclusive in participatory design. The cyclic processes of these two activities are the most important for continuous value creation. This paper proposed a basic framework for combining them, exemplified by tourism products designed by individual tourists and travel agency. The design processes for tourism products require several issues to be solved, which are as follows:

- Sophistication of design activities, as found in manufactured products.

- Innovation of customer touch points, as found in information and communication services.

- Diversity in customer preferences and activities, as found in services for individuals.

- Accommodation of requirements via direct oral communication, as found in concierge services.

Therefore, aiming at innovation in tourism by encouraging design by non-designers would play an important role in establishing a strong research basis for the manufacturing industry.

\section{Acknowledgement}

This research is supported by Service Science, Solutions and Foundation Integrated Research Program, Research Institute of Science and Technology for Society (RISTEX), Japan Science and Technology Agency (JST). We would like to express appreciation to Mr. Harri Karjalainen and Prof. Tomohiko Sakao, Linköping University for the cooperation of literature survey in Section 2.

\section{References}

[1] Storbacka, K., and Lehtinen, J. R., 2001, Customer relationship management: creating competitive advantages through win-win relationship strategies, McGraw-Hill Book Co.

[2] Tan, A.R., Matzen, D., McAloone, T.C., Evans S., 2010, Strategies for designing and developing services for manufacturing firms, CIRP Journal of Manufacturing Science and Technology, 3/2: 90-97.

[3] Hu, S.J., et al., 2010, Assembly System Design and Operations for Product Variety, Annals of CIRP Annals, 60/2:715-733.

[4] Arai, T., Shimomura, Y., 2004, Proposal of Service CAD System-A Tool for Service Engineering, Annals of CIRP 53/1:397-400.

[5] Shimomura, Y., Hara, T., and Arai, T., 2009, A Unified Representation Scheme for Effective PSS Development, Annals of CIRP, 58/1:379-382.

[6] Hara, T., Arai, T., Shimomura, Y., Sakao, T., 2009, Service CAD System to Integrate Product Behavior and Service Activity for Total Value, In CIRP Journal of Manufacturing Science \& Technology, CIRP, 1/4:262-271.

[7] Payne, A. F., Storbacka, K., and Frow, P.,2008, Managing the co-creation of value, Journal of the Academy of Marketing Science, 36:83-96.

[8] Vargo, S. L., \& Lusch, R. F., 2004, Evolving to a New Dominant Logic for Marketing, Journal of Marketing, 68:1-17.

[9] Ueda, K., Takenaka, T., Vancza, J., Monostori, L, 2009, Value Creation and Decision-making in Collaborative Society, Annals of CIRP Annals, 58/2:681-700.

[10] Silveira, D. G., Borenstein, D., and Fogliatto, F. S., 2001, Mass customization: Literature review and research directions, International Journal of Production Economics, 72/1:1-13.

[11] Hu, S.J., Zhu, X., Wang, H., Koren, Y., 2008, Product variety and manufacturing complexity in assembly systems and supply chains, Annals of CIRP Annals, 57/1:45-48.

[12] Gilmore, J. H., Pine, J. B., 1997, The Four Faces of Mass Customization, Harvard Business Review , January 1997:91-101.

[13] Tseng M.M., Jiao R.J., Wang C., 2009, Design for mass personalization, Annals of CIRP Annals, 59/1:175-178.

[14] Sanders, E. B.-N., 2006, Design Research in 2006, Design Research Quarterly, 1/1:1-8.

[15] Mahr, D., Lievens, A., 2012, Virtual lead user communities: Drivers of knowledge creation for innovation, Research Policy, 41:167-177.

[16] Lettl, C., 2007, User involvement competence for radical innovation, Journal of Engineering and Technology Management, 24: 53-75.

[17] JST RISTEX S3FIRE Program: http://www.ristex.jp/servicescience/EN/

[18] Kurata, Y., 2011, CT-Planner2: More Flexible and Interactive Assistance for Day Tour Planning, Law, R., Fuchs, M., and Ricci, F. (eds.) ENTER 2011, Information and Communication Technologies in Tourism 2011:25-37.

[19] Carroll, J.M. Rosson, M.B., 1987, The paradox of the active user, In J.M. Carroll (Ed.), Interfacing Thought: Cognitive Aspects of Human-Computer Interaction, Cambridge, MA: MIT Press. 